\title{
Entrevista
}




\section{Lições e problemas da universidade}

$\mathrm{P}$

assado um quartel de século desde a implantaçáo da reforma no ensino superior no Brasil, a questão da universidade, a partir da experiência da Universidade de São Paulo - esse foi o tema apresentado por Estudos Avanf̧ados ao reitor, professor Roberto Leal Lobo e Silva Filho, nessa entrevista feita pelo jornalista Marco Antônio Coelho.

Estudos Avançados - É chegada a bora de se proceder a uma avaliação da reforma do ensino superior realizada nos anos 60 ? Qual seria o papel da USP numa reformulafăo da universidade brasileira?

Roberto Lobo - Nos meios universitários são diversas as opinióes sobre as consequências e os resultados da reforma realizada no ensino superior do Brasil no final da década de sessenta. Muita gente tem dúvidas, faz críticas e propóe meios de contornar as dificuldades. Mas esse exame ainda não ganhou a dimensáo e a profundidade necessárias. Ademais, nos vinte anos transcorridos desde a reforma até hoje, o Brasil evoluiu e novas exigências são feitas pela sociedade brasileira às universidades. O que reclama um "aggiornamento" das reflexóes sobre o que fazemos na educação de terceiro e quarto graus em nosso país.

Em sendo assim, é útil estimular-se esse debate, mas compreendendo que envolve problemas complexos e diversificados, que não podem ser enfrentados de forma precipitada. Nessa reformulação o papel da Universidade de São Paulo é muito significativo, porque nela é que apareceram nas últimas décadas as mudanças na vida universitária brasileira. Nosso estatuto serviu de base para os de outras universidades e, assim, se no futuro decidirmos alterá-lo, é inevitável o surgimento de um debate nacional, no plano dos conceitos, sobre nosso ensino superior. Essa é mais uma razão para a necessidade de prudência no delineamento de alteraçōes dentro da própria USP. Por isso tenho algumas opinióes sobre a questáo, opinióes meramente pessoais que inclusive poderáo ser retificadas no curso do debate. 


\title{
Um balanço da reforma
}

\author{
Estudos Avançados - $O$ que houve de positivo e negativo naquela \\ reforma?
}

Lobo - O que de mais positivo houve naquela reforma? O básico foi se ter implantado, a partir dos anos setenta, a pós-graduação. No período de apenas vinte anos o Brasil se colocou num posição consolidada no nível da educação de quarto grau. Quanto à reforma no ensino de graduação, praticamente copiamos o modelo norte-americano, mas sem chegarmos às últimas consequências, o que costuma acontecer todas as vezes que se copia um modelo sem se ter a cultura do original.

Ao instituirmos a pós-graduação foi dado um passo de fundamental importância com a criaçáo concomitante de institutos voltados para a pesquisa básica, que, anteriormente, era desenvolvida dentro das faculdades dedicadas à formação de profissionais (médicos, dentistas, farmacêuticos, veterinários, engenheiros, agrônomos, etc.).

Assim, a Química era matéria em diversas faculdades, o que dificultava a pesquisa básica em Química, pois os docentes e pesquisadores dessa área trabalhavam de forma desarticulada, mal se comunicavam. Colocar essas pessoas juntas foi importante para melhorar a qualidade, melhorar o desempenho, aumentar a comunicaçáo entre elas.

Outro exemplo - a criação do Instituto de Ciências Biomédicas, juntando docentes de várias faculdades (Medicina, Veterinária e áreas afins) também abriu um caminho mais fecundo para o desenvolvimento da pesquisa básica nesse campo do conhecimento. $O$ resultado é incontestável: hoje possuímos no Brasil uma pesquisa básica que, em termos de qualidade e quantidade, é em média superior ao que existia antes da reforma universitária.

\section{Estudos Avançados - A reforma trouxe problemas para a gradua- ఢ⿳亠口冋o?}

Lobo - A mudança gerou problemas na graduaçăo. Ou seja a submissão da pesquisa básica à área profissional evoluiu para o quadro oposto, para a total independência da área básica face àquelas que preparam profissionais. Isso não foi bom. Antes da reforma, um professor de Física numa escola de Engenharia ministrava seu curso considerando que seus alunos destinavam-se à Engenharia. $O$ fato de esse professor estar numa escola de Engenharia o forçava a um diálogo permanente com os outros docentes dedicados à formação de engenheiros. Mas 
quando foi criado o Instituto de Física essa relação se diluiu. E tal fato ocorreu também com os outros institutos - Química e Matemática.

Outro exemplo: um estudante que fez o vestibular para Medicina, durante os dois anos que passa na área básica nem sequer entra na $\mathrm{Fa}$ culdade de Medicina. Nos Estados Unidos é diferente porque lá uma Faculdade de Medicina tem o nível de pós-graduação. Entre nós o que se vê é um desentrosamento entre o projeto do estudante e o que lhe é oferecido na universidade. Há casos até gritantes, como o que me foi contado pelo professor Oswaldo Lopes: alunos de Veterinária receberem lições sobre a hipertensão, quando tal anomalia, excluindo o ser humano, não é um problema para os animais. Então, o que observo é que nas áreas básicas nossos cursos dão ênfase ao que os especialistas da área acham importante ou interessante e ficam às vezes distantes das demandas específicas das faculdades profissionais.

Esse é um dos lados negativos decorrentes da reforma, do fato de termos copiado o modelo norte-americano pela metade, trazendo em consequência uma certa desmotivação entre muitos estudantes na fase em que estáo na área básica. A superaçáo disso é uma das questóes que hoje devemos examinar.

\section{A extinção das cátedras}

\section{Estudos Avançados - Era necessário acabar com o sistema de cáte- dras vitalícias?}

Lobo - Um dos pontos mais importantes na reforma universitária de 1968 foi a extinção das cátedras. Havia um aspecto positivo no sistema de cátedras: a responsabilidade individual do catedrático pela qualidade do curso e das pesquisas em seu setor. O catedrático tinha amor próprio em relação à excelência do curso e se o trabalho dos assistentes apresentava falhas o problema recaía sobre o catedrático e ele podia ser cobrado por isso nas reunióes da congregação.

Todavia, em contraste, eram gritantes os graves inconvenientes do sistema, a partir de erros nos concursos para catedráticos e pelo fato desses serem vitalícios na funçáo. Nos concursos, em razão da política interna na faculdade ou até mesmo por motivos subalternos, era frequente a não aprovação dos melhores candidatos à cátedra. $\mathrm{E}$ face $\mathrm{a}$ uma decisão equivocada num concurso, para a deficiência do catedrático não havia remédio até sua aposentadoria ou morte. 
Sendo aprovado no concurso, o catedrático podia até mesmo deixar de fazer pesquisa e de dar aulas, podia designar maus assistentes, etc. Em consequência, a muitas pessoas competentes, de qualidade comprovada, eram fechadas as portas para o ingresso na vida acadêmica. Assim, o sistema era repressor em relação aos novos talentos, era um obstáculo à melhoria do ensino superior. Portanto, foi um passo necessário e acertado a extinçáo do sistema de cátedras e da vitaliciedade do catedrático. Mas, em contrapartida, a diluição de responsabilidade nos departamentos está mal resolvida.

\section{A questão dos departamentos}

Estudos Avançados - Como o reitor vé os departamentos e qual o futuro deles numa universidade como a USP?

Lobo - No balanço dos resultados da reforma do ensino superior a estrutura e o funcionamento dos departamentos devem ser postos em questão. Assim penso porque os departamentos não têm rosto, não têm uma fisionomia nítida, são conceitualmente mal definidos e passaram a ser um dos focos de corporativismo dentro das universidades.

Por que isso acontece? Em primeiro lugar essas distorçóes podem ser ilustradas pelos próprios procedimentos estabelecidos para a escolha dos dirigentes de departamento. Pelas normas vigentes, o departamento tem total autonomia dentro da faculdade e/ou instituto; são os membros do departamento que escolhem o conselho departamental e este, por sua vez, deve traçar as diretrizes e elege o chefe. $O$ chefe não tem nenhum aval fora do próprio departamento! $O$ resultado não podia ser outro: o chefe não tem autoridade para gerir o departamento, uma vez que depende de seus subordinados e porque está preso ao jogo de influências dentro do departamento.

Como o conselho do departamento não estabelece as prioridades e não faz o acompanhamento dos relatórios, quando decide sobre as questóes do dia-a-dia, ele tende a ser corporativista. Porque num grande colegiado não há cobrança de responsabilidade e ninguém é demitido, por mais incompetente que seja.

O reitor da universidade é escolhido em lista tríplice que, no caso das universidades paulistas, vai para a apreciação e decisão da instância superior, que é o governador de São Paulo. Os diretores das faculdades e institutos saem também de listas tríplices que são submetidas ao reitor. Já o chefe de departamento é escolhido diretamente dentro desse órgão, 
o que demonstra que o departamento tem mais autonomia que a própria universidade.

O procedimento para a escolha do chefe de departamento subverte as normas que prevalecem para o preenchimento do cargo de reitor $\mathrm{e}$ dos diretores de faculdades e institutos, quando instâncias mais altas também opinam nessas escolhas. Por que numa universidade pública essa interferência é justa? Porque a universidade pública - organizada e mantida pelo Estado - tem obrigaçóes para com a sociedade e não é independente do Poder Público. Este, portanto, representando a sociedade, tem o direito e o dever de interferir na indicação do reitor. Processo que se efetiva, como todos sabem, através da nomeação de uma pessoa entre os indicados numa lista apresentada pela comunidade acadêmica. Processo correto e democrático porque conjuga o interesse mais geral da comunidade com a opiniáo da universidade.

No caso da nomeação dos diretores de faculdades e institutos, a reitoria igualmente participa uma vez que, junto com a opiniáo dos que militam nas faculdades e institutos, também devem ser levados em conta os projetos gerais da universidade, estabelecidos pelo seu conselho universitário. Por isso é uma distorção o mesmo princípio não ser adotado nos departamentos.

Essa distorção gera uma situação paradoxal na vida universitária, pois um determinado projeto que levou um diretor de faculdade ou instituto a ser eleito nada significa para o departamento, desde que este, gozando total autonomia, pode adotar uma orientação diversa à da faculdade e do instituto. Dizendo de outra forma, decidindo com autonomia plena sobre seu destino, o departamento se desincorpora do projeto global da faculdade, do instituto e da própria universidade.

\section{Um absurdo ainda maior}

\section{Estudos Avançados - É possivel uma universidade funcionar sem departamentos?}

Lobo - Quando se formula uma crítica à estrutura de nossos departamentos, logo surge a indagação formulada nessa pergunta. Respondo pela afirmativa e baseio meu ponto de vista recorrendo à experiência norte-americana, pois, ao contrário do que se pensa, em suas universidades em geral não há departamentos. $O$ que lá se denomina departamento corresponde ao nosso instituto. O que é o Department of Physics? É o nosso Instituto de Física. Eles chamam de departamento 
porque sua estrutura universitária é diferente da nossa. Eles têm o "dean", responsável pela grande área. Por exemplo, o "dean" de Ciências Exatas, que, na verdade, é o intermediário entre as faculdades e o reitor. Depois desse "dean" vêm os departamentos: de Física, de Química, de Matemática, etc. Mas nenhum dispóe de uma sub-estrutura interna, a não ser uma forma de grupos de pesquisa.

Então, como já afirmei, nós copiamos mal a experiência norteamericana. Copiamos apenas um pedaço, conservando uma parte da estrutura que já existia, uma vez que as pessoas não se libertam inteiramente do passado. Agrega-se o que é novo, mas não se descartam privilégios antigos. Não absolutizo a minha opinião contrária aos departamentos, porque em alguns casos ele são necessários, como depois exemplificarei. O que parece mesmo indispensável é a reorganizaçáo dos departamentos pequenos, dos que reúnem poucos docentes. Isto porque, além dos problemas inerentes a todos departamentos - problemas aqui assinalados - esses departamentos pequenos apresentam outros aspectos negativos.

Esses departamentos pequenos têm a pretensão de cobrir todas funçóes da universidade em sua área do conhecimento - ensino, pesquisa e extensão. Ora, isso é impossível com dez ou vinte docentes. $O$ trabalho desses professores seria mais produtivo se eles estivessem ligados a outros grupos de docentes nas atividades de ensino, pesquisa e extensão. Seria um grande avanço para a USP, por exemplo, se o ensino de graduação fosse responsabilidade das unidades.

O básico é que a segmentação excessiva dos departamentos acabou os mediocrizando, fazendo a universidade perder massa crítica, quando ela precisa de massa crítica notadamente quando enfrenta problemas muito complexos. Em suma, as distorçóes e falhas dos departamentos se acentuam quando apenas reúnem um reduzido número de professores.

É prejudicial a divisão dos institutos e faculdades em departamentos. Entretanto, no caso de uma escola como a Politécnica da USP, com cerca de $\mathbf{5 0 0}$ docentes, sua gestão reclama que talvez seja dividida em três grandes departamentos - de Engenharia Civil, de Engenharia Elétrica e Eletrônica e de Engenharia de Materiais, áreas suficientemente amplas, capazes de permitir o bom funcionamento desses três segmentos.

Equivalentemente, se poderia pensar em três institutos de áreas de engenharia, ligados a um coordenador de engenharias. Essa estrutura de três departamentos se justifica ainda mais porque de fato a Engenharia 
Civil e a Eletro-Eletrônica têm pouca necessidade de integraçăo. Mas dentro da Elétrica é necessário separar em departamentos de computação, potência, energia, micro-eletrônica?. Todas são parte de um corpo mais ou menos comum, principalmente nas atividades de ensino. Sendo assim, por que subdividir a Elétrica em diversos segmentos? Ademais, hoje a tendência nas universidades do mundo é de agregar disciplinas, professores e pesquisadores, evitando sempre que possível a proliferação de grupos de atividades independentes.

\section{A polêmica questão das "eleições diretas"}

Estudos Avançados - Depois do fim do regime militar em algumas universidades brasileiras seus dirigentes passaram a ser eleitos pelos professores, alunos e servidores, em eleiçóes diretas e em igualdade de condiçoes para os trés segmentos. Quais os resultados dessa experiencia?

Lobo - Na fase posterior ao fim do regime militar eclodiu com força a tendência a se adotar com exagero a idéia de que as "bases" é que devem tomar nas máos as rédeas da conduçáo da vida acadêmica. Chegou-se ao ponto de até serem instituídas "eleiçóes diretas" para reitor, dando direito de voto, em igualdade de condição, aos professores, servidores e alunos. Assim aconteceu em algumas universidades federais, com resultados catastróficos. Mas logo se compreendeu o malefício de tal procedimento. Contudo, persiste ainda um resquício desse equívoco - na estrutura dos departamentos. Daí a necessidade de agora se reequacionar essa questáo, levando-se em conta que a universidade não é um país, um estado ou um município, que elegem seus governantes para resolverem seus problemas. A universidade é um órgáo de prestação de serviços (ensino, pesquisa e extensão) e sua finalidade não é prioritariamente a satisfação da comunidade interna, mas prestar seus serviços à sociedade.

\section{Desafios da graduação}

\section{prioridade? \\ Estudos Avançados - Por que a USP agora coloca a graduafāon como \\ Lobo - Como afirmei de início, o resultado mais positivo da re- forma no ensino superior do Brasil, no fim da década de 60, foi a im- plantação dos cursos de pós-graduação. Um preço foi pago por isso: o relativo abandono da graduaçáo e a obsolência de muitas de suas áreas. \\ Então, é preciso retomar a questão da graduaçáo como sendo uma prio- ridade. Para retomá-la somos forçados a colocá-la como prioridade. Esse}


é o meu pensamento, desde que é muito grande a responsabilidade da USP perante a sociedade e com nossos $\mathbf{3 5}$ mil alunos na graduaçáo. $O$ futuro desses jovens em grande medida está na dẹpendência de sua formação em nossos campi. Em alguns meios certos analistas defendem a opiniāo que se deve continuar dando prioridade à pós-graduaçáo, argumentando que esta é uma exigência do desenvolvimento científico do País.

É impossível a uma universidade como a USP desempenhar bem suas tarefas se a sua graduação for deficiente, pois é impraticável termos pesquisadores de ponta se a graduação não alimentar a pós-graduação com alunos competentes. A sobrevivência de nossa pós-graduaçáo, de nossa pesquisa e de nossa renovação de quadros depende da qualidade na graduação. Ela é a essência da universidade e influi em tudo. Numa universidade como a USP quem dá o padrão da pós-graduaçáo são os egressos da graduação. (Um exemplo - numa turma de pós-graduação em Engenharia, $70 \%$ são formados aqui).

De outro lado, a sociedade brasileira espera um médico, por exemplo, sendo menos relevante essa pessoa ter mestrado em Medicina. Entre um estudante secundário e um médico essa diferença para a sociedade é mais notável do que a distância entre um médico e um mestre ou doutor em Medicina. Devemos classificar a graduaçáo como prioritária porque ela é que determina uma modificação básica na trajetória de um estudante, o que nitidamente se reflete na sociedade, sob inúmeros aspectos.

A graduação precisa formar um profissional competente, que pode não ser um pesquisador, um cientista, mas que deve ter a capacidade de se manter atualizado acompanhando a literatura especializada. Quer dizer, um médico deve ter a capacidade de acompanhar a literatura médica. Não digo literatura de biologia molecular. Ele tem de se atualizar, mesmo sem acompanhar a evolução das áreas pioneiras da Ciência. Um profissional é uma pessoa que sabe aplicar os conhecimentos científicos em sua atuaçáo como profissional. Mesmo que não domine o jargão científico, ele deve ser capaz de aplicar os conhecimentos científicos em sua profissão. Essas são algumas das exigências e os limites de um bom profissional, formado na graduação. Vale a pena refletir-se sobre o livro de Ortega y Gasset sobre a universidade.

Então, concluindo, na presente fase é prioritária a graduação, seguindo o preceito bíblico de "a cada dia, os seus cuidados", porque somente assim será encurtada a distância entre a qualidade da graduação e a qualidade da pós-graduação. 


\section{A estrutura das universidades}

\section{Estudos Avançados - Que alteraçóes deveriam ser feitas na legisla- füo sobre o ensino superior?}

Lobo - Um balanço dos resultados da reforma do ensino superior, promovida há vinte anos, naturalmente levará a mudanças na legislação sobre a matéria, inclusive porque tais modificações são impostas por preceitos novos colocados na Constituição de 1988.

De saída, julgo que uma nova legislação deve assegurar liberdade maior às universidades, considerando as diversidades existentes entre elas. Essa maior liberdade é uma decorrência do artigo 207 da Constituição Federal, ao estabelecer "a autonomia didático-científica, administrativa e de gestão financeira e patrimonial" das universidades.

Mas as mudanças na legislação deparam com uma dificuldade: o Brasil ainda não tem um projeto de ensino superior. Existe, isso sim, um cartório de ensino superior e se pensa que as universidades devem ser julgadas por um padrão igual para todas. Como isso é inviável, o padrão fica flexível em demasia e não há um processo de avaliação do desempenho de cada universidade, tendo $\mathrm{em}$ vista seu projeto específico.

A solução para esse problema ainda não apareceu. Julgo que avançaremos se duas premissas forem respeitadas: liberdade para as universidades fixarem seus normas e o estabelecimento de exigências de avaliação - interna e externa - do desempenho de cada uma. Em outras palavras, liberdade e cobrança maior. Hoje, não há nada disso. Por exemplo, se uma universidade encaminha uma proposta de curso, de antemão tudo está resolvido, porque apenas se verifica se nele foi dado o currículo mínimo e porque náo se acompanha os resultados do curso. A situação de descontrole é tal que talvez seja o caso de se pedir a um comitê nacional ou internacional de especialistas que examine se cada uma das universidades brasileiras deve mesmo ser chamada de universidade e se esse ou aquele curso deve ser aceito como um curso universitário.

Mas, ao se pesquisar as mudanças necessárias na estrutura universitária, o fundamental é a busca de caminhos para nosso ensino superior deixar de ser um cartório. Desde que, no Ministério da Educação, tudo gira em torno de exigências burocráticas, formais, que nada têm a ver com a vida real, com o que verdadeiramente sucede nas salas de aula e nos laboratórios de nossas escolas e universidades. 
Entretanto, ao colocar em questão a estrutura da universidade brasileira, tenho dúvidas, diante de tantas coisas que devem ser feitas de imediato, se compensa encaminhar agora uma proposta de uma nova reforma do ensino superior, o que fatalmente provocaria uma nova consolidaçáo que se não for bem amadurecida pode ficar reacionária e engessar nossa universidade em algumas décadas.

Assim, penso que agora o melhor será aguardarmos os resultados de certas iniciativas para, posteriormente, chegarmos a uma proposta de uma nova reforma no ensino superior do País. Vendo o panorama da USP, quais são essas iniciativas e essas inovaçóes? Diversos projetos estão aparecendo e alguns tabus estão caindo, por isso estamos conseguindo vencer restriçốes ao trabalho de extensão e à aproximação maior com as atividades industriais, amplia-se a agregação interdisciplinar na pós-graduação e há um empenho maior em aperfeiçoar a graduação, etc.

\section{A experiência norte-americana de direção das universi- dades}

Estudos Avançados - $A$ introdução do modelo norte-americano no Brasil foi bem feita?

Lobo - Na pesquisa de novos caminhos para a universidade brasileira é útil considerarmos melhor o modelo norte-americano, apenas parcialmente copiado por nós. dades.

Vejamos alguns pontos relacionados com a direção das universi-

A estrutura das universidades norte-americanas é mais rica do que a nossa. Numa universidade padrão (não todas), existe o "president", pessoa que dirige o "board of trustees", que faz a grande política da universidade, das relaçóes com o Poder Público e com a sociedade. Subordinado ao "president" há o "provost", que normalmente cuida das atividades acadêmicas nas áreas de ensino, pesquisa e extensão e é o encarregado do "follow-up", da continuidade entre a decisão e a execuçáo. Creio que devemos pensar na introduçáo dessa estrutura em nossas grandes universidades, porque no Brasil os reitores cuidam de tudo (até do número de serventes numa faculdade), têm de representar a universidade em todos os lugares, têm de dialogar com as autoridades e o público, além de responderem pelos trabalhos acadêmicos.

Nos EUA, além dos coordenadores setoriais ("deans" de graduaçáo, de pós-graduação, de pesquisa e de extensão), eles possuem os 
"deans" responsáveis pelas grandes áreas - ciências exatas, biológicas e humanas. Para aliviar a carga de trabalho que recai nas costas dos reitores das universidades brasileiras, a sugestão apresentada até agora tem sido a de os reitores delegarem a outras pessoas algumas de suas funçóes. Em meu modo de ver, essa não é a solução ideal, uma vez que a delegação não resolve se as funçốes não tiverem um expresso respaldo estatutário e regimental.

É verdade que nem essa estrutura mais complexa é capaz de aliviar o reitor americano que tem outras funçōes sociais e de contato com ex-alunos, com competiçóes esportivas, etc., que, além de fugirem à nossa cultura e ao nosso projeto de universidade, são altamente consumidoras de tempo, como na reitoria da universidade de Cincinnati.

\section{As atividades interdisciplinares}

Estudos Avançados - Como o reitor pl a tendencia mundial de serem estimuladas as atividades interdisciplinares nas unipersidades?

Lobo - O trabalho interdisciplinar nas universidades é indispensável, antes de tudo, porque os problemas reais e concretos são interdisciplinares. Serve como exemplo o desafio da necessidade de o rio Tietê ser despoluído, questáo em que somos obrigados a recorrer, simultaneamente, a engenheiros, químicos, biólogos, geólogos, sanitaristas, urbanistas, etc. Assim, o trabalho interdisciplinar é a única forma de resolvermos questóes complexas, agregando pesquisadores de várias especialidades.

$\mathrm{Na}$ USP estamos preocupados em estimular e organizar atividades interdisciplinares porque essa é uma imposição do extraordinário avanço dos conhecimentos científicos e tecnológicos nas últimas décadas. A experiência mais destacada que temos na USP é o curso de Ciências Moleculares, envolvendo biólogos, físicos e químicos. Outra experiência são algumas pesquisas procedidas no Instituto de Estudos Avançados, em que colaboram docentes de diversas unidades da USP e de outras universidades $e$, inclusive, pessoas que não pertencem aos círculos acadêmicos. Na USP temos programas de pós-graduação interdisciplinares, como é o caso do Programa de Integração da América Latina, Ciência Ambiental, etc.

Por isso numa futura reforma do ensino superior esse é um ponto que merece ser contemplado e que antes náo foi equacionado, pois a estrutura das universidades foi montada no Brasil visando a se atender à 
divisāo tradicional e rígida das disciplinas acadêmicas, estrutura implantada no século passado na Europa.

Aliás, quando proponho que seja examinada a questáo dos departamentos, também levo em consideraçáo o intuito de criarmos maiores facilidades para as atividades interdisciplinares. Todavia, quero deixar claro que não devemos ter como objetivo formar pesquisadores interdisciplinares, generalistas, porque ninguém é competente se se dedica ao mesmo tempo a diversas áreas do conhecimento. A meta é outra: é a aglutinação de competências em diversas áreas, em função de um trabalho conjunto, em função de projetos interdisciplinares.

\section{Trabalho de equipe}

\section{Estudos Avançados - Há um retrocesso do trabalho de pesquisa em equipe nas universidades?}

Lobo - Alguns colegas julgam que o trabalho de equipe nas atividades de pesquisa diminuiu com a reforma do ensino superior em consequência da extinção das cátedras e com a total autonomia dada a cada doutor. Realmente, houve um retrocesso no trabalho de pesquisa em equipe. Mas, atribuo esse fato principalmente à política que foi e é adotada pelas agências de financiamento - como o CNPq e a FAPESP, que valorizam excessivamente $o$ auxílio individual aos pesquisadores sem que procedam um exame que deveria ser mais rigoroso da competência do pesquisador $\mathrm{e}$ da prioridade do projeto.

Para se estimular o trabalho em equipe, porém, a soluçáo não está numa volta ao passado, não está em hierarquizar-se funçóes, com a obrigação dos docentes de seguirem planos de pesquisas determinados pelos professores titulares ou os livre-docentes. Não. Em princípio não sou contra um doutor ter auxílio financeiro para desenvolver um projeto que é somente seu, mas esse projeto deve ser realmente excepcional e esse pesquisador deve ser realmente muito competente e criativo. Um cientista do gabarito de um César Lattes, por exemplo, deve receber todo o apoio de que necessita, pois sáo pessoas como ele que fazem descobertas notáveis em Ciência e Tecnologia. O que discordo é das facilidades excessivas na concessáo de financiamentos à pesquisa, como no chamado " balcão" do CNPq. Procedimento que guarda até alguma semelhança com o clientelismo, hoje táo criticado na vida política do País.

Acabando com essa prática de se atender a todos que solicitam apoio financeiro para suas pesquisas, mataríamos dois coelhos com uma 
só cajadada. Estimularíamos o trabalho em equipe e se terminaria também com essa divisão maldita de recursos, com a pulverizaçáo dos mesmos, resultante da entrega de migalhas a muiros - tanto para os projetos bons como para os projetos ruins. Modificando-se essa política, sabendo que o financiamento não mais seria concedido facilmente pelas agências, naturalmente os pesquisadores se agregariam em equipes, porque teriam consciência que somente os projetos bem feitos com boas perspectivas de sucesso e desenvolvidos por equipes é que teriam maior possibilidade de serem aprovados pelas agências.

Enfim, para incentivarmos o trabalho de pesquisa em equipe devemos mexer no "nervus rerum" (no nervo das coisas), no dinheiro. Isso é básico ainda mais porque são escassos os recursos dedicados ao investimento em Ciência e Tecnologia.

\section{O problema da avaliação}

Estudos Avançados - Qual a importancia da avaliafáo das atividades universitárias? Como a USP está enfrentando essa questão?

Lobo - Para o aperfeiçoamento do ensino superior no Brasil é indispensável encontrarmos uma solução para um problema crucial: como se instituir um sistema de avaliação do desempenho de nossas escolas e universidades.

Nos meios de comunicaçáo é frequente se afirmar que a sociedade reclama maior eficiência das universidades. Analisando essa crítica, o que sinto é que a sociedade brasileira ainda não sabe o que deve cobrar das universidades, porque náo acompanha o que é feito nas escolas e nos campi.É certo que muitas críticas são formuladas a aspectos de corrupção, de mordomias, de desperdícios, etc, que são visíveis em diversas escolas e universidades do País. No entanto, esse tipo de críticas, muitas vezes procedentes, diz respeito a erros em qualquer um dos segmentos do serviço público - como ministérios, prefeituras e assim por diante. Não é uma cobrança sobre aquilo que precisamente a universidade tem a obrigaçáo de produzir.

Outra coisa: os defeitos das universidades mais discutidos muitas vezes não são os seus defeitos reais, ou não são os seus defeitos mais graves. Um exemplo - praticamente não há críticas ao fato de nossas universidades não escolherem áreas de atuaçã́o mais relacionadas com os problemas nacionais e regionais agudos. Hoje, não está mais na moda se dizer que essa é uma conduta alienada, mas, na verdade, isso não é uma alienação? 
Em contrapartida, cabe acrescentar que nas escolas e universidades não facilitamos o debate sobre falhas porque temos uma carapaça grossa de auto-proteção. Que se revela inclusive no curioso fato de entre nós haver até receios de se elogiar ou destacar méritos de alguns de nossos professores e pesquisadores. Porque o elogio a uns e o silêncio sobre outros, redunda numa crítica a estes últimos. Essa carapaça de auto-proteçáo dificulta, sem dúvida, a instituição de um sistema permanente de avaliação de nosso trabalho.

Para não perdermos o rumo e para náo nos embaraçarmos ante tantas dificuldades, que premissas devem ser assentadas para montar-se esse sistema de avaliaçáo? Penso, em primeiro lugar, que essa avaliação somente chegará às questões básicas quando o Brasil possuir um projeto de desenvolvimento que também passe pela universidade, um projeto de desenvolvimento que reclame a elevação da capacitaçáo científica e tecnológica do Brasil. Porque no dia em que a opiniāo pública sentir que o conhecimento é imprescindível para impulsionarmos nosso desenvolvimento social e econômico, nesse dia ela cobrará mais das universidades, elas serão forçadas a um empenho maior no esforço para o Brasil enfrentar os desafios que atormentam a Nação.

Contudo, devemos reconhecer que é muito difícil se avaliar atividades educacionais, mesmo porque seus resultados - positivos ou negativos - só aparecem a médio e longo prazo. Portanto, a avaliaçăo de nosso trabalho é algo muito mais complexo do que avaliar-se a qualidade de um bem material - um automóvel, por exemplo. Em sendo assim, temos de recorrer a determinados indicadores, como número de artigos publicados, número de formandos, número sobre evasão de estudantes, etc e etc. Mas, tais indicadores isoladamente podem falsear a realidade e por isso é imprescindível cautela na sua manipulação.

Para não ficar em consideraçóes gerais sobre o processo de avaliação em nosso ensino superior, creio ser mais útil relacionar o que estamos fazendo na USP face à questão. Nos próximos meses estaráo definidas as propostas de avaliação elaboradas pelos próprios professores.

Para tanto, estão sendo discutidos indicadores de produtividade. Desses, a maior parte refere-se à carga didática, mas depois seráo incorporados indicadores sobre a produçáo de pesquisas.

No momento estão sendo definidos os critérios pelos quais os departamentos desejam ser avaliados. De início serão avaliados 100 dos 250 departamentos da USP. Esse levantamento irá demorar cerca de dois anos, consumindo recursos da ordem de $\mathbf{2 0 0}$ mil dólares. Isto por- 
que participarāo da avaliação pessoas não pertencentes aos quadros da USP, mas de outras universidades brasileiras e estrangeiras, além de especialistas que atuam no mercado profissional.

Esse processo de avaliação se dividirá em duas fases. Na primeira, o próprio chefe de departamento responderá a um questionário sobre produção científica, sobre a qualidade da graduaçáo e outros itens. $\mathrm{Na}$ segunda fase, as comissóes externas à USP farão um diagnóstico, assinalando falhas e apresentando sugestões, além de formularem comparaçóes com cursos similares existentes no Brasil e no Exterior.

No panorama geral, então, hoje na USP existe um consenso sobre a necessidade de um sistema de avaliaçáo, quando anteriormente se considerava um despropósito, uma perda de tempo e até uma ofensa se realizar uma avaliação de nossas atividades e a tendência é de, no futuro, se dar a cada departamento verbas orçamentárias de conformidade com o seu desempenho e com seus projetos de atividades.

Em resumo, é nosso propósito fazer com que esse processo e avaliação seja permanente e não como um sentido punitivo, mas sim para estimular uma melhor desempenho de nossos docentes, pesquisadores e servidores, a fim de aperfeiçoarmos toda a gestão da Universidade de São Paulo.

Estudos Avançados - Acha que os pontos aqui abordados envolvem as principais reflexōes a serem feitas pela universidade na década de 90 ?

Lobo - Não. Estamos conversando há um bom tempo, mas a universidade é um tema por demais abrangente para se exaurir nos limites de uma entrevista. Já disse, respondendo à primeira pergunta, que alguns dos meus pontos de vista podem até sofrer uma retificação posterior, em debate mais amplo. Minha concordância em falar livremente, em ritmo de pingue-pongue, tem no máximo o mérito de ajudar a montagem de um cenário maior de opiniôes, na hora própria. Quando chegará essa hora? Somente a dinâmica dos fatos poderá determiná-la. Os desafios práticos, dentro da Universidade, são tão intensos que talvez desaconselhem a precipitação de um debate de natureza tão marcantemente conceitual. Isso poderia, inclusive, afastar-nos perigosamente de projetos prioritários que estamos implementando. Conduzido pelas perguntas que foram feitas, deixei de abordar várias questóes relevantes. Espero ter oportunidade de voltar ao assunto em ocasiáo propícia. 